\title{
Surveillance of human immunodeficiency virus suggests that younger men who have sex with men are at higher risk of infection, European Union, 2003 to 2012
}

J Janiec (janusz.janiec@ecdc.europa.eu) ${ }^{1,2}$, K Haar $^{1}$, G Spiteri ${ }^{1}$, G Likatavicius ${ }^{1}$, M Van de Laar $^{1}$, A J Amato-Gauci ${ }^{1}$

1. European Centre for Disease Prevention and Control (ECDC), Stockholm, Sweden

2. National Institute of Public Health- National Institute of Hygiene, Warsaw, Poland

Citation style for this article:

Janiec J, Haar K, Spiteri G, Likatavicius G, Van de Laar M, Amato A. Surveillance of human immunodeficiency virus suggests that younger men who have sex with men are at higher risk of infection, European Union, 2003 to 2012. Euro Surveill. 2013;18(48):pii=20644. Available online: http://www.eurosurveillance.org/

ViewArticle.aspx?Articleld=20644

Article submitted on 19 November 2013 / published on 28 November 2013

In 2012, newly reported human immunodeficiency virus diagnoses in the European Union /European Economic Area remained stable at around 30,000 cases. Since 2003, cases in men who have sex with men (MSM) aged 20 to 29 years-old doubled, while the proportion of late presenters in this group remained stable. Persistent declines occurred among older MSM age groups, particularly that between 30 and 39 yearsold. Interventions targeting younger MSM are needed to prevent a resurgence of the epidemic in Europe.

Since 2008, the European Centre for Disease Prevention and Control (ECDC), together with the World Health Organization (WHO) Regional Office for Europe, has been coordinating an enhanced human immunodeficiency virus (HIV)/acquired immunodeficiency syndrome (AIDS) surveillance for European Union (EU) Member States and European Economic Area (EEA) countries. The 2012 data collection and analysis offered the opportunity to re-examine the distribution and trends of HIV infection by risk and age group.

Human immunodeficiency virus infections in the European Union/European Economic Area In 2012, a total of 29,381 new HIV diagnoses were reported by $30 \mathrm{EU} / \mathrm{EEA}$ countries, resulting in a rate of 5.8 per 100,000 population [1]. When adjusted for reporting delay [2], this figure rises to 30,900 cases and a rate of 6.2 per 100,000 population [1] Notification rates in men and women were 9.1 and 2.7 per 100,000 , respectively, for a male-to-female ratio of 3.2. Among all new HIV diagnoses $(29,381)$, young people aged 15 to 24 years accounted for $11 \%(3,114)$ of all the new HIV diagnoses reported. The largest proportion of new diagnoses, however, was observed among 30 to 39 year-olds $(33 \%, 9,782)$.

Between 2006 and 2012, the overall rate of reported diagnoses in EU/EEA countries decreased by $3 \%$ when adjusting for reporting delay (from 6.4 to 6.2 per 100,000 population). During this time, 14 countries reported decreasing rates whereas increases were reported in 16 countries. The highest proportion of new HIV diagnoses in 2012 continued to be reported among men who have sex with men (MSM) (40\%, 11,877 cases), followed by heterosexual transmission (34\%, 9,944 cases). The latter includes $12 \%(3,474$ cases $)$ of heterosexually-acquired cases originating from subSaharan African countries with generalised epidemics. People who inject drugs (PWID) accounted for $6 \%$ $(1,785$ cases $)$ of all HIV cases.

\section{FIGURE 1}

Proportion of men who have sex with men among newly reported male human immunodeficiency virus cases in 2012 in 15 European Union Member States, 2012 $(\mathrm{n}=11,774)$

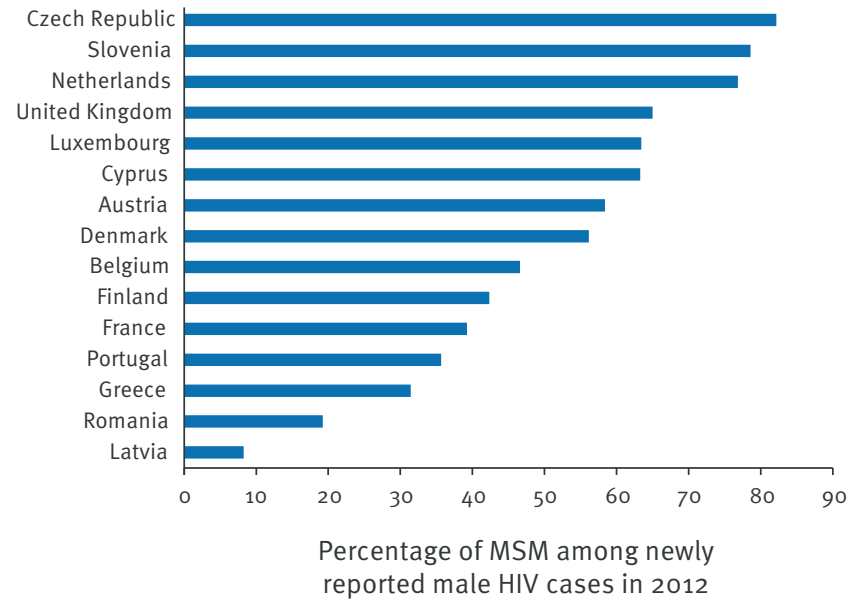

HIV: human immunodeficiency virus; MSM: men who have sex with men.

The 15 countries in the Figure include those which reported the mode of transmission for more than $50 \%$ of their cases and consistently reported $\mathrm{CD}_{4}$ counts for the period from 2003 to 2012. 


\section{FIGURE 2}

Distribution of newly reported HIV cases through men who have sex with men transmission by year and age group among 15 European Union Member States, 2003$2012(n=59,992)$

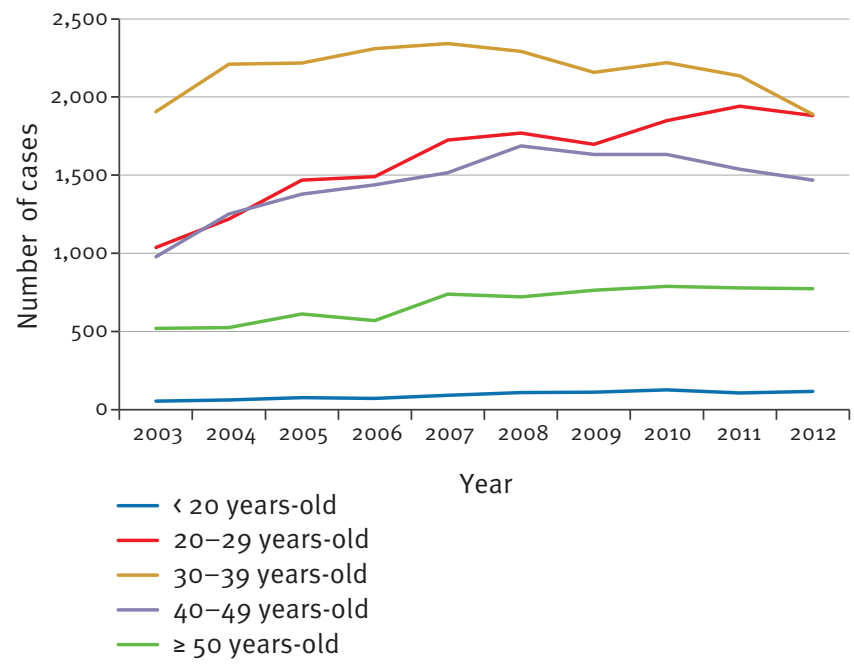

HIV: human immunodeficiency virus.

The data in the Figure originate from 15 European Union Member States, which reported the mode of transmission for more than $50 \%$ of their HIV cases and consistently reported CD4 counts for the period from 2003 to 2012 .

These 15 countries include Austria, Belgium, Cyprus, Denmark, the Czech Republic, Finland, France, Greece, Latvia, Luxembourg, the Netherlands, Portugal, Romania, Slovenia and the United Kingdom.

Data on CD4 cell count at the time of HIV diagnosis for more than $50 \%$ of cases were provided by 19 countries (overall completeness in 2012: 56\%). Among these countries 16,150 cases were reported, of which 7,924 (49\%) were categorised as 'late presenters' (CD4 cell count less than $350 / \mathrm{mm}^{3}$ ), including 4,759 (30\%) of cases with advanced HIV infection (CD4 $\left.2000 / \mathrm{mm}^{3}\right)$. The highest proportion of late presenters was observed among heterosexually-acquired cases ( $59 \%, 3,817$ of 6,472 ), especially among those originating from subSaharan countries $(62 \%, 1,454$ of 2,361$)$, the lowest among cases due to mother-to-child (23\%, 18 of 80 ) and MSM $(38 \%, 2,857$ of 7,458$)$ transmission.

\section{New human immunodeficiency virus} diagnoses and late presentation in men who have sex with men in the European Union

The analysis included data from 15 countries reporting between 2003 and 2012 which had recorded the mode of transmission for more of $50 \%$ of their cases and consistently reported $\mathrm{CD}_{4}$ counts. Among these countries, the proportion of MSM transmission reported among men in 2012 were highest in the Czech Republic 82\% (152 of 185 cases), Slovenia 79\% (33 of 42 cases) and the Netherlands $77 \%$ (636 of 828 cases) (Figure 1 ).

In the 15 countries included in the analysis, the number of reported HIV diagnoses among MSM increased by
$36 \%$, from a total 4,501 cases in 2003 to 6,130 cases in 2012; the number of cases has remained stable since the peak of 6,585 cases in 2008 . Trends by age group varied (Figures 2 and 3): among males aged 20 to 29 years, the number of cases during this period almost doubled from 1,037 to 1,881 cases ( $81 \%$ increase). However, among very young MSM under 20 years-old, a much smaller group, an even larger increase was observed from 54 to 116 cases. An increase in cases among MSM younger than 29 years-old was also observed at individual country level in the majority of the 15 countries, reflecting the overall increase.

CD4 cell counts were available for 38,463 HIV diagnoses reported among MSM between 2003 and 2012, increasing from 2,149 cases in 2003 to 4,588 in 2012. In 2012 , of 4,588 cases acquired through MSM contact, $37 \%(1,691$ cases) were categorised as late presenters and $18 \%$ ( 845 cases) presented with advanced HIV infection. These figures show improvement since 2003 , when of 2,149 cases, the proportion of late presenters and cases with advanced infection at the time of HIV diagnosis were $45 \%$ (974 cases) and $25 \%$ (537 cases), respectively. The largest drop in the proportion of late presenters was among 30 to 39 year-olds (19\% in 2003 , 406 cases of 2,149 , down to $11 \%$, in 2012,493 of 4,588 ) (Table). In all other age groups, the proportion of late

\section{FIGURE 3}

Proportion of HIV newly reported cases among MSM by age group among 15 European Union Member States, $2003-2012(n=59,992)$

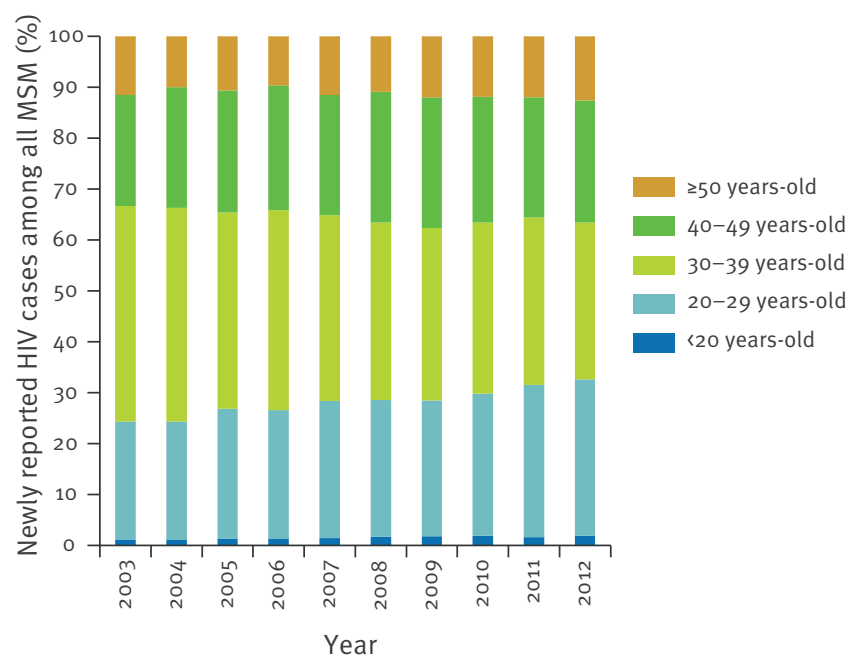

HIV: human immunodeficiency virus; MSM: men who have sex with men.

The data in the Figure originate from 15 European Union Member States, which reported the mode of transmission for more than $50 \%$ of their HIV cases and consistently reported CD4 counts for the period from 2003 to 2012.

These 15 countries include Austria, Belgium, Cyprus, Denmark, the Czech Republic, Finland, France, Greece, Latvia, Luxembourg, the Netherlands, Portugal, Romania, Slovenia and the United Kingdom. 
Percentage of cases reported to have a CD4 cell count $<350 / \mathrm{mm}^{3}$ among all MSM HIV cases with known CD4 counts, by age group, among 15 European Union Member States, 2003-2012 ( $\mathrm{n}=59,992)$

\begin{tabular}{|c|c|c|c|c|c|c|c|c|c|c|}
\hline \multirow{2}{*}{ Age group in years } & \multicolumn{10}{|c|}{ Percentage of cases among MSM HIV cases with a $\mathrm{CD} 4$ cell count $1350 / \mathrm{mm}^{3}$, by year } \\
\hline & 2003 & 2004 & 2005 & 2006 & 2007 & 2008 & 2009 & 2010 & 2011 & 2012 \\
\hline$<20$ & 0.47 & 0.35 & 0.34 & 0.20 & 0.39 & 0.30 & 0.25 & 0.52 & 0.46 & 0.39 \\
\hline $20-29$ & 7.72 & 7.21 & 8.30 & 8.64 & 8.64 & 8.46 & 7.59 & 8.01 & 8.15 & 8.65 \\
\hline $30-39$ & 18.89 & 15.90 & 16.80 & 14.77 & 13.69 & 14.04 & 12.33 & 11.82 & 12.05 & 10.75 \\
\hline $40-49$ & 10.75 & 11.67 & 10.64 & 11.92 & 11.98 & 11.91 & 11.93 & 11.45 & 10.25 & 10.09 \\
\hline$>50$ & 7.49 & 6.93 & 5.68 & 5.99 & 7.34 & 6.48 & 6.59 & 6.54 & 5.93 & 6.97 \\
\hline All & 45.32 & 42.07 & 41.77 & 41.52 & 42.05 & 41.20 & 38.69 & 38.35 & 36.83 & 36.86 \\
\hline
\end{tabular}

HIV: human immunodeficiency virus; MSM: men who have sex with men.

The data in the Table originate from 15 European Union Member States, which reported the mode of transmission for more than $50 \%$ of their HIV cases and consistently reported CD4 counts for the period from 2003 to 2012.

These 15 countries include Austria, Belgium, Cyprus, Denmark, the Czech Republic, Finland, France, Greece, Latvia, Luxembourg, the Netherlands, Portugal, Romania, Slovenia and the United Kingdom.

presenters among all newly diagnosed HIV cases remained fairly stable.

\section{Discussion and conclusion}

The EU/EEA 2012 surveillance data indicate that new HIV infections remain concentrated in key populations at higher risk of HIV infection, such as MSM, heterosexual people originating from high-endemic countries and, to a lesser extent, people who inject drugs. European surveillance data are heavily dependent on national testing strategies, good case-detection and comprehensive reporting of all cases on a national and European level. Reporting the mode of transmission is key to allow the correct interpretation of data and to improve targeted prevention. Unfortunately, stigma and limited access to low-threshold healthcare facilities still hamper the disclosure of sexual preference in many countries [3] and this is likely to result in underreporting of MSM transmission [4].

The relatively high proportion of late diagnoses in many countries is a worrying indication of delays in accessing HIV testing. Although we found a stable prevalence of late diagnosis among young MSM (20 to 29 years-old), the concomitant increase in absolute numbers of new HIV infections in this age group is worrying as well. A study from an Australian state whereby testing for HIV among MSM was performed, revealed that MSM under the age of 35 years were more likely than older MSM to have never previously been tested for HIV. In 20 cities in the United States (US) awareness of HIV-positive status in 2008 and in 2011 among MSM increased significantly by age $[5,6]$. A modelling study among MSM based on the Swiss HIV Cohort Study estimated that by the end of $2010,13.5 \%$ of infected MSM were undiagnosed, however they were estimated to account for almost $82 \%$ of new infections due to continuing risky sexual behaviour [7], hence the conclusion by the authors that HIV testing needs to be scaled up.

The increases in new HIV infections among young MSM aged 20 to 29 years reported here are similar to findings during the period between 1994 and 2011 in the US and Australia [5,8-10]. In Norway, although an increase in new HIV cases was found to have occurred from 2003 to 2011, no difference in median age (36 years) among these newly diagnosed HIV cases was observed among MSM between 1995 and 2011 [11]. In Australia, Canada, Germany, the Netherlands, the United Kingdom and the US, the weighted median age was even found to have increased from 34 to 36 years between 1996 and 2005 [12]. Studies showing increasing trends in co-infections with other sexually transmitted infections (STIs) [11-14] suggest high levels of sexual risk behaviour among MSM that augments the likelihood of acquiring HIV and hence might be one of the reasons for the increase in young MSM reported here [11-15].

In Australia, increases in new HIV infections, particularly in young MSM, were found to be strongly correlated with increasing trends, since 1998, of MSM younger than 30 years not taking combination antiretroviral therapy (CART) [8]. In Scotland, younger MSM ( 25 years-old) increasingly engaged in higher levels of sexual risk behaviour ( 2 or more partners with unprotected anal intercourse in the previous 12 months) between 2000 and 2002 [16] and which could be a driving factor for the increasing trends.

In the data presented here we saw a decrease in late presenters in 30 to 39 year-old MSM, which supports the hypothesis that testing increased in this age group over the last decade, probably due to increased 
awareness among older MSM [6] or changing testing strategies over time. Despite this, access to and uptake of testing still needs to improve as $37 \%$ of all new infections in MSM in 2012 presented at a stage where treatment is already needed.

There are several limitations in this analysis and the results presented. First, data submitted over the years are incomplete, particularly for $\mathrm{CD}_{4}$ cell count, and our interpretation might be biased as cases for which no information on CD4-cell count was given might differ from those reported. To overcome this issue, we strictly limited our analysis to those countries which consistently reported the mode of transmission for more than $50 \%$ of cases as well as the CD4 cell count in all years analysed. Second, our results are influenced by countries with large numbers of new HIV infections and a concomitant complete reporting of the mode of transmission. Third, surveillance data is prone to delays in reporting and underreporting. In our MSM analysis, we did not take the reporting delay into account and data for 2012 might still underestimate the true picture. This analysis also does not take into account changes in HIV testing strategies and reporting patterns.

In the last decade, the largest increase in new infections has been seen among young MSM. Throughout Europe, HIV counselling and testing services need to be continuously promoted, made more accessible and targeted at key populations at higher risk to ensure earlier diagnosis and initiation of HIV treatment and linkage to care [17]. This will result in improved treatment outcomes and clinical benefits, as well as contribute to preventing or further reducing HIV transmission.

\section{Acknowledgements}

We would like to thank National HIV Contact Points from countries participating in the European network for HIV/ AIDS surveillance: Austria: Klein Jean Paul; Belgium: Andre Sasse; Bulgaria: Tonka Varleva; Cyprus: Avgi Hadjiloukas; Czech Republic: Marek Maly; Denmark: Susan Cowan; Estonia: Kristi Rüütel; Finland: Kirsi Liitsola; France: Caroline Semaille; Germany: Osamah Hamouda; Greece: Georgios Nikolopoulos, Dimitra Paraskeva; Hungary: Mária Dudás; Iceland: Haraldur Briem; Ireland: Kate O'Donnell; Italy: Barbara Suligoi; Latvia: Šarlote Konova; Lithuania: Saulius Čaplinskas; Luxembourg: Jean Claude Schmit; Malta: Jackie Maistre Melillo; Netherlands: Eline op de Coul; Norway: Hans Blystad; Poland: Magdalena Rosinska; Portugal: Helena Cortes Martins; Romania: Mariana Mardarescu; Slovakia: Peter Truska; Slovenia: Irena Klavs; Spain: Mercedes Diez Ruiz-Navarro; Sweden: Frida Hansdotter; United Kingdom: Valerie Delpech. We would like also to thank ECDC colleagues for their contributions, especially Chantal Quinten, Phillip Zucs, Denis Coulombier, Johan Giesecke, the TESSy team and Valentina Lazdina.

\section{Conflict of interest}

None declared.
Authors' contributions

JJ developed the concept of the manuscript, collected and analysed the data, wrote the first draft of the manuscript and responded to reviewer comments. $\mathrm{KH}$ contributed to the concept of the manuscript, interpreted the results critically, contributed to writing the manuscript and revised the article to ensure important intellectual content. GS contributed to the concept of the manuscript and analysis, contributed to writing the manuscript and revision of the article. MvL, GL and $A A$ developed the surveillance instrument, critically reviewed the article and provided important feedback on the article. All authors read and approved the final manuscript.

\section{References}

1. European Centre for Disease Prevention and Control (ECDC), World Health Organization Regional Office for Europe. HIV/ AIDS Surveillance in Europe 2012. Stockholm: ECDC; 2013.

2. Heisterkamp SH, Jager IC, Ruitenberg EJ, Van Druten JA, Downs AM. Correcting reported AIDS incidence: a statistical approach. Stat Med. 1989;8(8):963-76. http://dx.doi.org/10.1002/ sim.4780080807. PMid:2799125

3. Berg RC, Ross MW, Weatherburn P, Schmidt AJ. Structural and environmental factors are associated with internalised homonegativity in men who have sex with men: findings from the European MSM Internet Survey (EMIS) in 38 countries. Soc Sci Med. 2013;78:61-9. http://dx.doi.org/10.1016/j. socscimed.2012.11.033. PMid:23261257.

4. The European Men-Who-Have-Sex-With-Men Internet Survey (EMIS) Network. EMIS 2010: The European Men-Who-HaveSex-With-Men Internet Survey. Findings from 38 countries. Stockholm: European Centre for Disease Prevention and Control; 2013. Available from: http://ecdc.europa.eu/en/ publications/Publications/EMIS-2010-european-men-whohave-sex-with-men-survey.pdf

5. El-Hayek C, Bergeri I, Hellard ME, Pedrana AE, Higgins N, Breschkin A, et al. The changing age distribution of men who have sex with men diagnosed with HIV in Victoria. Med J Aust. 2010;193(11-12):655-8. PMid:21143052.

6. Wejnert C, Le B, Rose CE, Oster AM, Smith AJ, Zhu J et al. HIV Infection and Awareness among Men Who Have Sex with Men-20 Cities, United States, 2008 and 2011. PLoS One. 2013;8(10):e76878. http://dx.doi.org/10.1371/journal. pone.0076878. PMid:24194848. PMCid:PMC3806782.

7. van Sighem A, Vidondo B, Glass TR, Bucher HC, Vernazza P, Gebhardt M, et al. Resurgence of HIV infection among men who have sex with men in Switzerland: mathematical modelling study. PLoS One. 2012;7(9):e44819. http://dx.doi.org/10.1371/ journal.pone.0044819. PMid:23024766. PMCid:PMC3443082.

8. Murray JM, Prestage G, Grierson J, Middleton M, McDonald A. Increasing HIV diagnoses in Australia among men who have sex with men correlated with the growing number not taking antiretroviral therapy. Sex Health. 2011;8(3):304-10. http:// dx.doi.org/10.1071/SH10114. PMid:21851769

9. Oster AM, Johnson CH, Le BC, Balaji AB, Finlayson TJ, Lansky $A$, et al. Trends in HIV Prevalence and HIV Testing Among Young MSM: Five United States Cities, 1994-2011. AIDS Behav. 2013 Aug 17. http://dx.doi.org/10.1007/s10461-013-0566-1

10. Prejean J, Song R, Hernandez A, Ziebell R, Green T, Walker F, et al. Estimated HIV incidence in the United States, 2006-2009. PLoS One. 2011;6(8):e17502. http://dx.doi.org/10.1371/journal. pone.0017502. PMid:21826193. PMCid:PMC3149556.

11. Jakopanec I, Grjibovski AM, Nilsen $\varnothing$, Blystad H, Aavitsland $P$. Trends in HIV infection surveillance data among men who have sex with men in Norway, 1995-2011. BMC Public Health. 2013;13:144. http://dx.doi.org/10.1186/1471-2458-13-144. PMid:23414557 PMCid:PMC3585925.

12. Sullivan PS, Hamouda O, Delpech V, Geduld JE, Prejean J, Semaille $C$, et al. Reemergence of the HIV epidemic among men who have sex with men in North America, Western Europe, and Australia, 1996-2005. Ann Epidemiol. 2009;19(6):423 31. http://dx.doi.org/10.1016/j.annepidem.2009.03.004 PMid:19460672.

13. Sasse A, Defraye A. HIV infections and STI co-infections in men who have sex with men in Belgium: sustained increase in HIV diagnoses. Euro Surveill. 2009;14(47): pii=19420. Available from: http://www.eurosurveillance.org/ViewArticle. aspx?Articleld $=19420$

14. Spielmann N, Münstermann D, Hagedorn $\mathrm{H}$, an der Heiden $\mathrm{M}$, Houareau C, Gunsenheimer-Bartmeyer B, et al. Time trends of syphilis and HSV-2 co-infection among men who have sex with men in the German HIV-1 seroconverter cohort from 
1996-2007. Sex Transm Infect. 2010;86(5):331-6. http://dx.doi. org/10.1136/sti.2009.040857. PMid:20876750.

15. Centers for Disease Control and Prevention (CDC). Notes from the field: repeat syphilis infection and HIV coinfection among men who have sex with men--Baltimore, Maryland, 20102011. MMWR Morb Mortal Wkly Rep. 2013;62(32):649-50. PMid:23945772.

16. Knussen C, Flowers P, McDaid LM, Hart GJ. HIV-related sexual risk behaviour between 1996 and 2008, according to age, among men who have sex with men (Scotland). Sex Transm Infect. 2011;87(3):257-9. http://dx.doi.org/10.1136/ sti.2010.045047. PMid:21071563. PMCid:PMC3272888.

17. Leutscher PD, Laursen T, Andersen B, Ostergaard L, Laursen A, Larsen CS. HIV late presenters in Denmark: need for increased diagnostic awareness among general practitioners. Dan Med Bull. 2011;58(4):A4253. PMid:21466763.

18. European Centre for Disease Prevention and Control (ECDC). HIV Testing: Increasing uptake and effectiveness in the European Union. Stockholm: ECDC; 2010. Available from: http://ecdc.europa.eu/en/publications/publications/101129_ gui_hiv_testing.pdf 